Received: 23 May 2017

Accepted: 24 July 2017

Published online: 18 August 2017

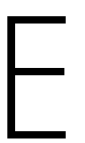

C N IF

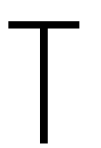

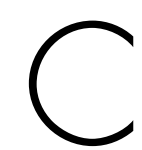

REP

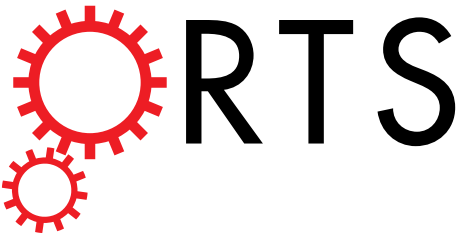

Highly efficient up-conversion luminescence in $\mathrm{Er}^{3+} / \mathrm{Yb}^{3+}$ co-doped $\mathrm{Na}_{5} \mathrm{Lu}_{9} \mathrm{~F}_{32}$ single crystals by vertical Bridgman method

\section{Shinan $\mathrm{He}^{1}$, Haiping Xia ${ }^{1}$, Jianli Zhang ${ }^{1}$, Yongsheng Zhu ${ }^{2}$ \& Baojiu Chen ${ }^{3}$}

$\mathrm{Er}^{3+} / \mathrm{Yb}^{3+}$ co-doped $\mathrm{Na}_{5} \mathrm{Lu}_{9} \mathrm{~F}_{32}$ single crystals with different concentrations of $\mathrm{Yb}^{3+}$ ions were prepared to investigate their phase structure, up-conversion (UC) properties and mechanism of UC luminescence by Bridgman method. Under $980 \mathrm{~nm}$ near-infrared (NIR) excitation, three sharp UC emission bands topping at green $\sim 525 \mathrm{~nm}, \sim 548 \mathrm{~nm}$ and red $\sim 669 \mathrm{~nm}$ were obtained in $\mathrm{Er}^{3+} / \mathrm{Yb}^{3+}$ doped $\mathrm{Na}_{5} \mathrm{Lu}_{9} \mathrm{~F}_{32}$ single crystals which are attributing to the transitions of ${ }^{2} \mathrm{H}_{11 / 2} \rightarrow{ }^{4} \mathrm{I}_{15 / 2,}{ }^{4} \mathrm{~S}_{3 / 2} \rightarrow{ }^{4} \mathrm{I}_{15 / 2}$ and ${ }^{4} \mathrm{~F}_{9 / 2} \rightarrow{ }^{4} \mathrm{I}_{15 / 2 \text {, }}$ respectively. The quadratic dependence of pump power on UC emission indicated that two-photon process is in charge of the transition from excited state of $\mathrm{Yb}^{3+}$ ions to lower state of $\mathrm{Er}^{3+}$ ion in $\mathrm{Na}_{5} \mathrm{Lu}_{9} \mathrm{~F}_{32}$ single crystals. The long-accepted mechanism for the production of red and green emissions through up-conversion (UC) under $980 \mathrm{~nm}$ excitation in $\mathrm{Er}^{3+} / \mathrm{Yb}^{3+}$ co-doped materials apply in the $\mathrm{Na}_{5} \mathrm{Lu}_{9} \mathrm{~F}_{32}$ host was displayed. The enhancement of the red emission was observed due to a cross-relaxation (CR) process of the form: ${ }^{4} \mathrm{~F}_{7 / 2}+{ }^{4} \mathrm{I}_{11 / 2} \rightarrow{ }^{4} \mathrm{~F}_{9 / 2}+{ }^{4} \mathrm{~F}_{9 / 2}$. Furthermore, an ideal yellowish green light performance could be achieved with $1.0 \mathrm{~mol} \% \mathrm{Er}^{3+}$ doped certain $\mathrm{Yb}^{3+}$ concentrations samples, and its external quantum efficiency approached to $6.80 \%$ under $5.5 \mathrm{Wcm}^{-2} 980 \mathrm{~nm}$ excitation which can be applied in developing UC displays for electro-optical devices.

Considerable interests in rare-earth (RE) doped UC phosphors have burgeoned since the development of synthetic methods for creating highly processable UC materials with applications in biolabeling ${ }^{1,2}$, sub-band gap energy harvesting in photovoltaics ${ }^{3,4}$, and security printing ${ }^{5}$. Due to its potential applications in biological fluorescence and volumetric displays, much effort has been devoted to the investigation on $\mathrm{UC}$ in $\mathrm{RE}^{3+}$ doped materials over the past years. Recently, a few basic works have been reported in order to explain the origin of the relatively high UC efficiencies ${ }^{6}$, the ability to adjust the color purity through manipulating dopant concentrations $^{7}$, and the special phenomenon that result from surface effects in nanoscale UC phosphors ${ }^{8,9}$.

Among all the rare-earth ions, $\mathrm{Er}^{3+}$ ion is one of the best candidates as an activator in up-conversion luminescence on account for its longer lifetimes of metastable energy levels and more homogeneous energy level array. By employing $\mathrm{Yb}^{3+}$ ions as sensitizer into $\mathrm{Er}^{3+}$ doped materials, the UC luminescence performance can be improved because of a larger absorption cross section at NIR of $\mathrm{Yb}^{3+}$ and the high-efficiency energy transfer from $\mathrm{Yb}^{3+}$ to $\mathrm{Er}^{3+}$ ions $^{10-12}$.

A number of researches on $\mathrm{Er}^{3+} / \mathrm{Yb}^{3+}$ co-doped systems have been focused on exploring the UC mechanisms and developing novel hosts in recent years ${ }^{13}$. In order to reduce the multi-phonon nonradiative relaxation and realize the high efficient UC luminescence, low maximum phonon energy hosts are required and necessary. Compared with the popular oxide materials, it is well-known that fluorides are more efficient hosts for $\mathrm{RE}^{3+}$ ions due to their low energy phonons to produce strong UC fluorescence. Up till now, fluorides like $\mathrm{Na}_{5} \mathrm{Lu}_{9} \mathrm{~F}_{32}$ have been investigated widely ${ }^{14-16}$. However, the studied materials of fluoride $\mathrm{Na}_{5} \mathrm{Lu}_{9} \mathrm{~F}_{32}$ mainly concentrate on nano-crystals and powders ${ }^{17}$, and the $\mathrm{Er}^{3+} / \mathrm{Yb}^{3+}$ co-doped UC materials have never been in-depth studied in $\mathrm{Na}_{5} \mathrm{Lu}_{9} \mathrm{~F}_{32}$ single crystals. Compared with nano-crystal, single crystal provides higher transmission for lights and

${ }^{1}$ Key laboratory of Photo-electronic Materials, Ningbo University, Ningbo, Zhejiang, 315211, China. ${ }^{2}$ College of Physics and Electronic Engineering, College of Chemistry and Charmaceutical Engineering, Nanyang Normal University, Nanyang, 473061, China. ${ }^{3}$ Department of Physics, Dalian Maritime University, Dalian, Liaoning Province, 116026, China. Correspondence and requests for materials should be addressed to H.X. (email: hpxcm@nbu.edu.cn) orY.Z. (email: yongshengzhu0001@163.com) 


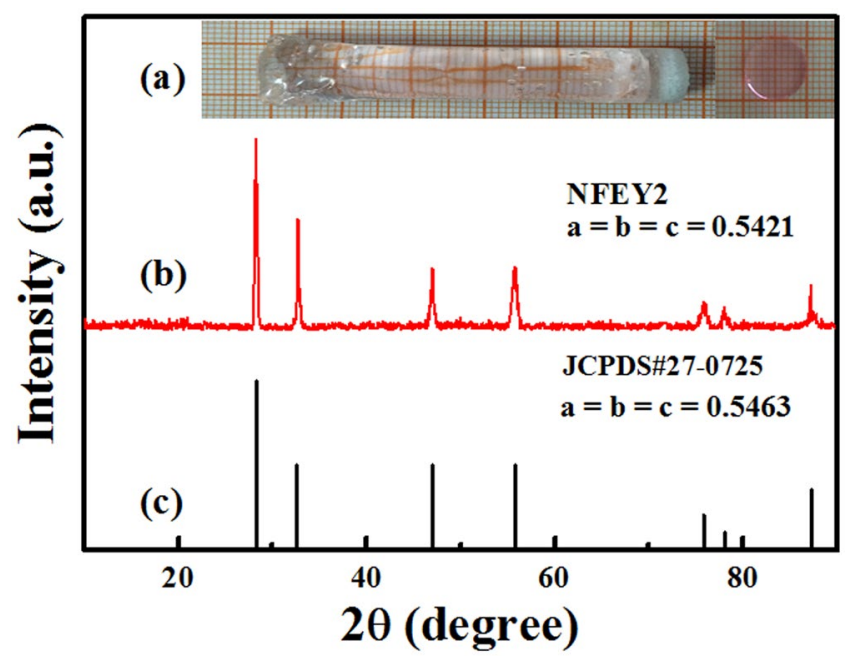

Figure 1. (a) The photo of $\mathrm{Na}_{5} \mathrm{Lu}_{9} \mathrm{~F}_{32}$ single crystal, the left is boule of the crystal and the right is polished slice. (b) XRD patterns of the $\mathrm{Na}_{5} \mathrm{Lu}_{9} \mathrm{~F}_{32}: \mathrm{Er}^{3+} / \mathrm{Yb}^{3+}$. (c) Standard line patterns of $\mathrm{Na}_{5} \mathrm{Lu}_{9} \mathrm{~F}_{32}(27-0725)$.

thermal stability as well as good chemical durability. There are scarce reports on $\mathrm{Na}_{5} \mathrm{Lu}_{9} \mathrm{~F}_{32}$ single crystals because of the difficulty in the crystal growth. Thus, $\mathrm{Na}_{5} \mathrm{Lu}_{9} \mathrm{~F}_{32}$ in form of single crystal is an excellent candidate matrix for $\mathrm{Er}^{3+} / \mathrm{Yb}^{3+}$ ions to investigate the UC luminescence spectra.

Generally, there exists the problem of the inhomogeneous distribution of RE ions in single crystal resulted from crystal growth. In this study, $\mathrm{Na}_{5} \mathrm{Lu}_{9} \mathrm{~F}_{32}$ single crystal was chosen as a matrix of $\mathrm{Er}^{3+}$ and $\mathrm{Yb}^{3+}$ ions in view of the same valence state and the very near ionic radii between $\mathrm{Lu}^{3+}(0.861 \AA)$ and $\mathrm{Er}^{3+}(0.881 \AA), \mathrm{Lu}^{3+}$ and $\mathrm{Yb}^{3+}$ $(0.858 \AA)$, which resulted in relatively homogeneous concentration of $\mathrm{Er}^{3+}$ and $\mathrm{Yb}^{3+}$ in $\mathrm{Na}_{5} \mathrm{Lu}_{9} \mathrm{~F}_{32}$ single crystal. The $\mathrm{Na}_{5} \mathrm{Lu}_{9} \mathrm{~F}_{32}$ single crystal with homogeneous rare earths is extremely important for the practical application in optical device.

\section{Results and Discussions}

Characteristics of $\mathrm{Na}_{5} \mathrm{Lu}_{9} \mathrm{~F}_{32}$ single crystal. In order to understand the structures and characteristics of the as-grown crystals, the crystallinity was confirmed in the X-ray powder diffraction (XRD) patterns as shown in Fig. 1(b). It can be seen from the XRD spectra of $\mathrm{Er}^{3+} / \mathrm{Yb}^{3+}$ co-doped $\mathrm{Na}_{5} \mathrm{Lu}_{9} \mathrm{~F}_{32}$ single crystal in Fig. 1(b), the structure of the single crystal was confirmed to be cubic phase, in accordance with JCPDS card (27-0725) of $\mathrm{Na}_{5} \mathrm{Lu}_{9} \mathrm{~F}_{32}$ as shown in Fig. 1(c), which the diffraction peak positions of the obtained samples doped with $\mathrm{Er}^{3+} /$ $\mathrm{Yb}^{3+}$ ions are matched perfectly with those of standard $\mathrm{Na}_{5} \mathrm{Lu}_{9} \mathrm{~F}_{32}$, though there exists a slight shift in the range of $0.10^{\circ}$ to $0.45^{\circ}$ as the dopant change, indicating that this transparent crystal has pure cubic phase. Moreover, the cell parameters were calculated by the following formula ${ }^{18}$

$$
d=\frac{a}{\sqrt{h^{2}+k^{2}+l^{2}}}
$$

Accordingly, the cell parameter is calculated to be $\mathrm{a}=0.5421 \mathrm{~nm}$ (space group Fm $3 \mathrm{~m}$ ) for sample NFEY2 $\left(0.99 \mathrm{~mol} \% \mathrm{Er}^{3+} / 1.97 \mathrm{~mol} \% \mathrm{Yb}^{3+}\right.$ sample) from the measured XRD patterns.

Absorption and transmittance spectra of the $\mathrm{Er}^{3+} / \mathrm{Yb}^{3+}$ co-doped $\mathrm{Na}_{5} \mathrm{Lu}_{9} \mathrm{~F}_{32}$ single crystal. The absorption spectra in the $400-1100 \mathrm{~nm}$ wavelength of the as-grown $\mathrm{Na}_{5} \mathrm{Lu}_{9} \mathrm{~F}_{32}$ single crystal samples has been measured and presented in Fig. 2(a). The absorption peaks corresponding to transitions from the ${ }^{4} \mathrm{I}_{15 / 2}$ ground state to excited states of the $\mathrm{Er}^{3+}$ ions are also assigned in Fig. 2(a). Compared the $\mathrm{Er}^{3+}$ singly-doped sample with $\mathrm{Er}^{3+} / \mathrm{Yb}^{3+}$ co-doped sample, there is nearly no intensity and position change for the shape of peaks in the visible region, where confirms that $\mathrm{Er}^{3+}$ ions can absorb visible light. As for the absorption center at $980 \mathrm{~nm}, \mathrm{Er}^{3+} / \mathrm{Yb}^{3+}$ co-doped sample shows an obvious peak located at $980 \mathrm{~nm}$ corresponding to the transition from ${ }^{2} \mathrm{~F}_{7 / 2} \rightarrow{ }^{2} \mathrm{~F}_{5 / 2}$ of $\mathrm{Yb}^{3+}$ ion, which demonstrates that $\mathrm{Yb}^{3+}$ ions acts as an excellent sensitizer to absorb the pump light. The corresponding UV-VIS-NIR transmittance spectrum of well polished $\mathrm{Er}^{3+} / \mathrm{Yb}^{3+}$ co-doped $\mathrm{Na}_{5} \mathrm{Lu}_{9} \mathrm{~F}_{32}$ single crystal with $1.5 \mathrm{~mm}$ thickness also showed in Fig. 2(b). It can be confirmed that the transmittance was measured to be $\sim 89 \%$ in the visible region $\left(\mathrm{Na}_{5} \mathrm{Lu}_{9} \mathrm{~F}_{32}\right.$ single crystals are highly transparent as shown in Fig. $\left.1(\mathrm{a})\right)$, which proves that there exists a high transmittance in the range of $400-1000 \mathrm{~nm}$.

Emission spectra and energy transfer of as-prepared $\mathrm{Na}_{5} \mathrm{Lu}_{9} \mathrm{~F}_{32}$ single crystal co-doped $1.0 \%$ $\mathrm{Er}^{3+}$ and $\chi \% \mathrm{Yb}^{3+}(\mathrm{X}=0,2,6,8)$. The quantitative comparison of up-conversion luminescence of as-prepared $\mathrm{Na}_{5} \mathrm{Lu}_{9} \mathrm{~F}_{32}$ single crystal co-doped $1.0 \% \mathrm{Er}^{3+}$ and $\chi \% \mathrm{Yb}^{3+}(\chi=0,2,6,8)$ under NIR 980 nm excitation have been shown in Fig. 3, from which three obvious bands in the range of 450-750 nm can be observed. As presented in Fig. 3, two green emissions around $525 \mathrm{~nm}$ and $548 \mathrm{~nm}$ are assigned to the radiative transition of ${ }^{2} \mathrm{H}_{11 / 2} \rightarrow{ }^{4} \mathrm{I}_{15 / 2}$ and ${ }^{4} \mathrm{~S}_{3 / 2} \rightarrow{ }^{4} \mathrm{I}_{15 / 2}$, respectively. And red emission band from 638 to $688 \mathrm{~nm}$ is attributed to the 

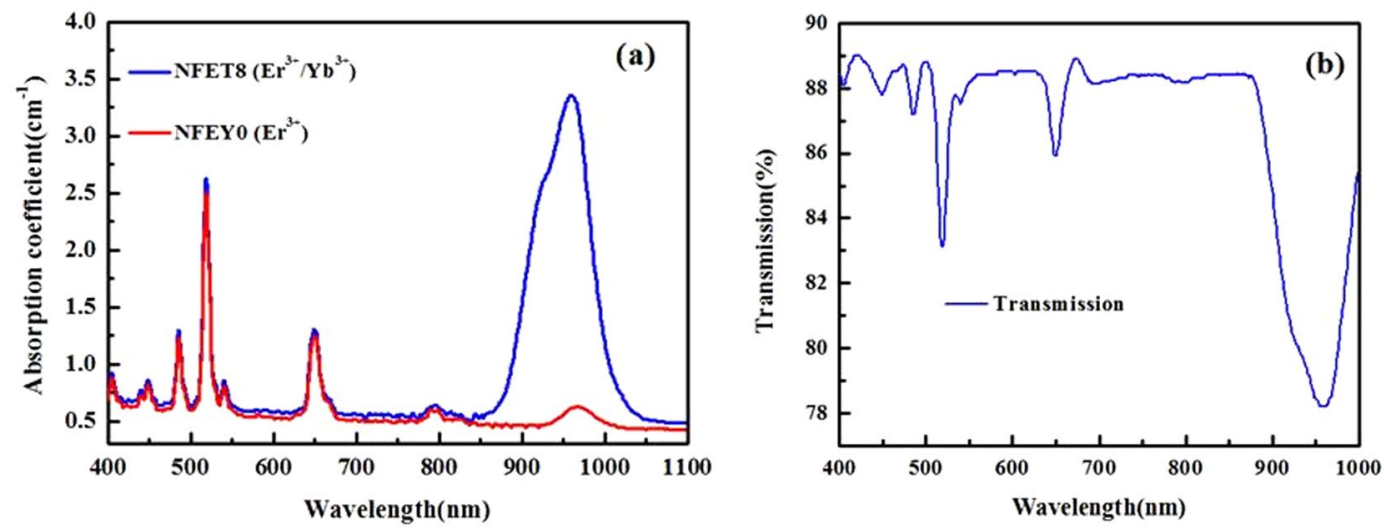

Figure 2. (a) Absorption spectra of $\mathrm{Er}^{3+} / \mathrm{Yb}^{3+}$ single doped and co-doped $\mathrm{Na}_{5} \mathrm{Lu}_{9} \mathrm{~F}_{32}$ single crystals. (b) Transmittance spectra of $\mathrm{Er}^{3+} / \mathrm{Yb}^{3+}$ co-doped $\mathrm{Na}_{5} \mathrm{Lu}_{9} \mathrm{~F}_{32}$ single crystal.



Figure 3. Comparison of the up-conversion luminescence spectra of $\mathrm{Er}^{3+} / \mathrm{Yb}^{3+}$ doped $\mathrm{Na}_{5} \mathrm{Lu}_{9} \mathrm{~F}_{32}$ single crystals under $980 \mathrm{~nm}$ excitation at room temperature; the inset shows the integrated total intensity on $\mathrm{Yb}^{3+}$ concentrations in $\mathrm{Er}^{3+} / \mathrm{Yb}^{3+}$ doped $\mathrm{Na}_{5} \mathrm{Lu}_{9} \mathrm{~F}_{32}$ single crystals.

${ }^{4} \mathrm{~F}_{9 / 2} \rightarrow{ }^{4} \mathrm{I}_{15 / 2}$ transition of $\mathrm{Er}^{3+}$ ion. Compared luminescence intensity of $\mathrm{Er}^{3+}$ single-doped sample with $\mathrm{Er}^{3+} / \mathrm{Yb}^{3+}$ co-doped $\mathrm{Na}_{5} \mathrm{Lu}_{9} \mathrm{~F}_{32}$ one, there is a distinct improvement of up-conversion luminescence efficiency when the $\mathrm{Yb}^{3+}$ ions take part in. The relative amount of $\mathrm{Yb}^{3+}$ sensitizer ions tend to obviously improve the up-conversion luminescence (UCL) intensity in $\mathrm{Er}^{3+} / \mathrm{Yb}^{3+}$ phosphors, thus we have investigated the impact of various ytterbium concentrations on the intensity of the UC emission under the same experiment condition. The insert of Fig. 3 shows the integrated total intensity on $\mathrm{Yb}^{3+}$ concentrations. The UCL intensity of $668 \mathrm{~nm}$ emission increases rapidly as the $\mathrm{Yb}^{3+}$ concentration increases and reaches its maximum value when $\mathrm{Yb}^{3+}$ concentration is $7.97 \mathrm{~mol} \%$ in present research, which is attributed to the aggravated cross-relaxation process of ${ }^{4} \mathrm{~F}_{7 / 2}+{ }^{4} \mathrm{I}_{11 / 2}-{ }^{4} \mathrm{~F}_{9 / 2}+{ }^{4} \mathrm{~F}_{9 / 2}$ with the increase of $\mathrm{Yb}^{3+}$ ions concentration. The concentration quenching of $\mathrm{Yb}^{3+}$ ions is not observed, while the maximum intensity of $548 \mathrm{~nm}$ and $525 \mathrm{~nm}$ emission is obtained when $\mathrm{Yb}^{3+}$ concentration is $1.99 \mathrm{~mol} \%$.

To reveal the origin of these radiations and the mechanism of the UC emissions, the decay profiles of $\mathrm{Na}_{5} \mathrm{Lu}_{9} \mathrm{~F}_{32}$ single crystal doped $\mathrm{Er}^{3+}$ with different amount of $\mathrm{Yb}^{3+}$ ions under $980 \mathrm{~nm}$ excitation at $548 \mathrm{~nm}$ is shown in Fig. 4, and the inset is the comparison of decay times centered at 525, 548 and $668 \mathrm{~nm}$ for $1.0 \% \mathrm{Er}^{3+} / 8 \%$ $\mathrm{Yb}^{3+}$ co-doped $\mathrm{Na}_{5} \mathrm{Lu}_{9} \mathrm{~F}_{32}$ single crystal. These decay profiles were fitted with non-exponential, the decay time of these radiations centered at 525, 548 and $668 \mathrm{~nm}$ show the similar value of $\sim 880 \mu$ s from the inset of the Fig. 4. Meanwhile, the lifetime for $1.0 \% \mathrm{Er}^{3+}$ singly doped $\mathrm{Na}_{5} \mathrm{Lu}_{9} \mathrm{~F}_{32}$ single crystal and $1.0 \% \mathrm{Er}^{3+} / \chi \% \mathrm{Yb}^{3+}(\chi=2,6,8)$ co-doped $\mathrm{Na}_{5} \mathrm{Lu}_{9} \mathrm{~F}_{32}$ single crystals are $\tau_{\mathrm{m}}=311.1 \mu \mathrm{s}, \tau_{\mathrm{m}}=1567.7 \mu \mathrm{s}, \tau_{\mathrm{m}}=1114.4 \mu \mathrm{s}, \tau_{\mathrm{m}}=870.4 \mu \mathrm{s}$ respectively. It suggests that there is no concentration quenching in present doping concentration. And it can be seen that the fluorescence for the co-doped crystals (NFEY2, 6, 8) decays more quickly than that for the single-doped one (NFEY0) from Fig. 4, which indicates an obvious enhancement of up-conversion luminescence efficiency arise from dopants of $\mathrm{Yb}^{3+}$ ions. As presented in Fig. 4, the lifetime of green emission decreased apparently when the concentration of $\mathrm{Yb}^{3+}$ ions increases, which can verify that cross-relaxation (CR) process of ${ }^{4} \mathrm{~F}_{7 / 2}+{ }^{4} \mathrm{I}_{11 / 2} \rightarrow{ }^{4} \mathrm{~F}_{9 / 2}+{ }^{4} \mathrm{~F}_{9 / 2}$ occurred. The $\mathrm{Na}_{5} \mathrm{Lu}_{9} \mathrm{~F}_{32}$ single crystal shows high incorporating concentrations for 


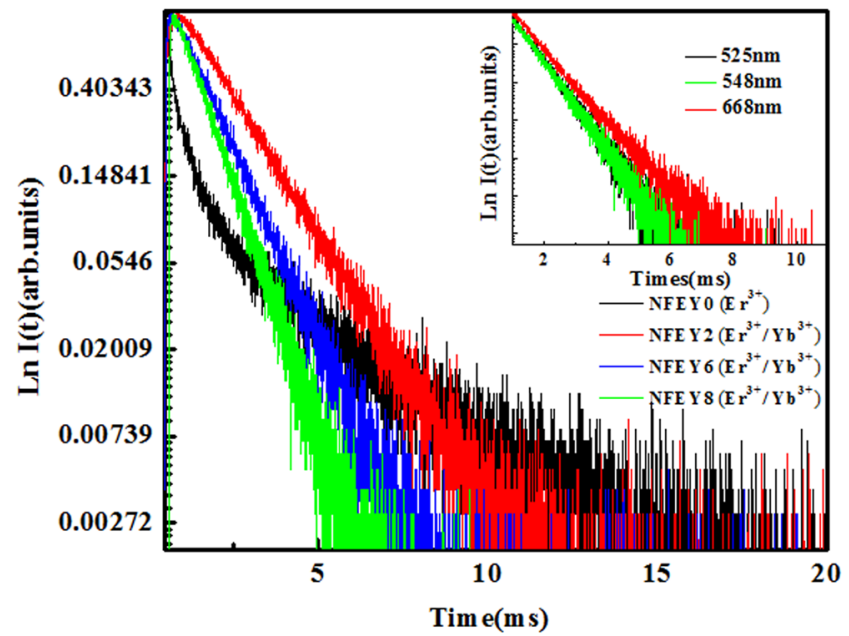

Figure 4. Decay curves of the $\mathrm{Er}^{3+} / \mathrm{Yb}^{3+}$ co-doped $\mathrm{Na}_{5} \mathrm{Lu}_{9} \mathrm{~F}_{32}$ single crystals surveyed at $548 \mathrm{~nm}$ under $980 \mathrm{~nm}$ excitation, and the inset is the decay times centered at 525,548 and $668 \mathrm{~nm}$ for $1.0 \% \mathrm{Er}^{3+} / 8 \% \mathrm{Yb}^{3+}$ co-doped $\mathrm{Na}_{5} \mathrm{Lu}_{9} \mathrm{~F}_{32}$ single crystal.

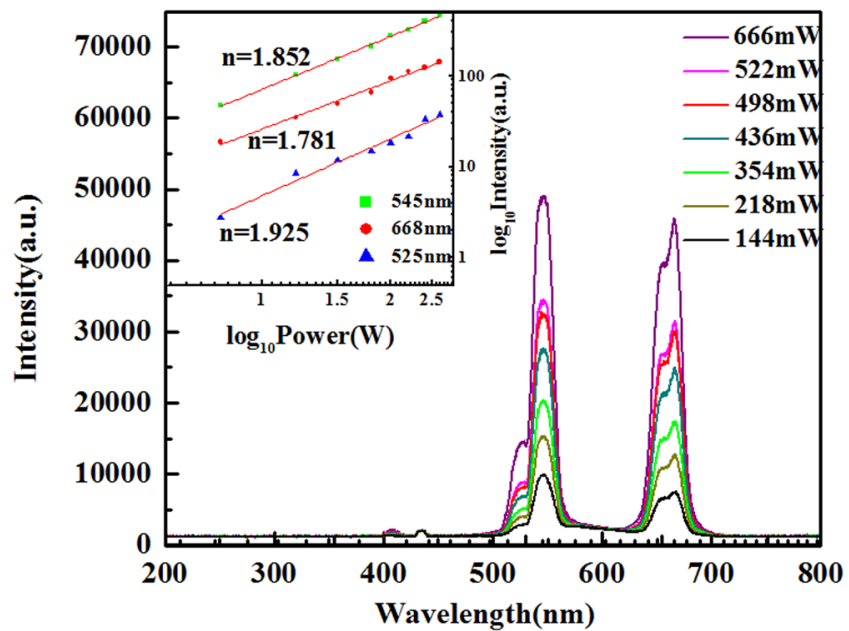

Figure 5. Log-log dependence of the up-conversion intensities of $1.0 \mathrm{~mol} \% \mathrm{Er}^{3+}$ and $7.97 \mathrm{~mol} \% \mathrm{Yb}^{3+}$ co-doped $\mathrm{Na}_{5} \mathrm{Lu}_{9} \mathrm{~F}_{32}$ single crystal at $525,548,668 \mathrm{~nm}$ emissions as a function of the excitation power at $980 \mathrm{~nm}$.

$\mathrm{Er}^{3+}$ and $\mathrm{Yb}^{3+}$. Owing to the similar radii size and same valence state of between rare earth ions, $\mathrm{Er}^{3+}$ ions and $\mathrm{Yb}^{3+}$ ions could easily take place of the position of $\mathrm{Lu}^{3+}$ in $\mathrm{Na}_{5} \mathrm{Lu}_{9} \mathrm{~F}_{32}$ single crystal. The homogeneity of REs in $\mathrm{Na}_{5} \mathrm{Lu}_{9} \mathrm{~F}_{32}$ can be reflected from the effective segregation coefficients of REs in single crystal and they can be estimated from the measured concentration and the formula $c=k c_{0}(1-f)^{(k-1)}$, where $c$ and $c_{0}$ express the concentrations of RE in single crystal and raw material, $\mathrm{k}$ is effective segregation coefficient of RE, and $\mathrm{f}$ is the crystallization rate ${ }^{19}$. The effective segregation coefficients for $\mathrm{Er}^{3+}$ and $\mathrm{Yb}^{3+}$ in $\mathrm{Na}_{5} \mathrm{Lu}_{9} \mathrm{~F}_{32}$ were about 0.990 and 1.013 , respectively, which approach to 1 . It indicates that a relatively homogeneous concentrations of REs can be obtained because of the very near ionic radii between $\mathrm{Lu}^{3+}(0.861 \AA)$ and $\mathrm{Er}^{3+}(0.881 \AA), \mathrm{Lu}^{3+}$ and $\mathrm{Yb}^{3+}(0.858 \AA)$ and results into high luminescence effect of $\mathrm{Er}^{3+}$ and $\mathrm{Yb}^{3+}$.

In order to investigate the $\mathrm{UC}$ dynamics of $\mathrm{Er}^{3+} / \mathrm{Yb}^{3+}$ co-doped $\mathrm{Na}_{5} \mathrm{Lu}_{9} \mathrm{~F}_{32}$ single crystal, the pump-power dependence of luminescence intensities was measured as a function of excitation power density under the $980 \mathrm{~nm}$ excitation. As shown in Fig. 5, the up-conversion luminescence intensities increased as excitation power increasing to the maximum $\sim 666 \mathrm{~mW}$, which may conclude that high excitation power can improve the up-conversion luminescence efficiency. It is known that the relation between emission intensity $\mathrm{I}_{\mathrm{em}}$ and NIR excitation power $\mathrm{I}_{\mathrm{em}} \propto \mathrm{P}^{\mathrm{n}}$ in frequency up-conversion process ${ }^{20}$, where $\mathrm{n}$ is the number of pump photons required to excite to the emitting state. From the log-log dependence of the integrated green $(\sim 525$ and $\sim 548 \mathrm{~nm})$ and red emission $(\sim 668 \mathrm{~nm})$ intensities on the excitation power at $980 \mathrm{~nm}$ shown in the inset of Fig. 5, the graph of $\log \left(I_{\text {em }}\right)$ versus $\log (\mathrm{P})$ yields a slope of $\mathrm{n}$ equal to approximately $1.968,1.852,1.721$, respectively. The value of $\mathrm{n}$ is approximately equal to 2, which implied the lower thermal effect and saturation effect in $\mathrm{Na}_{5} \mathrm{Lu}_{9} \mathrm{~F}_{32}: \mathrm{Yb}^{3+}, \mathrm{Er}^{3+}$ single 


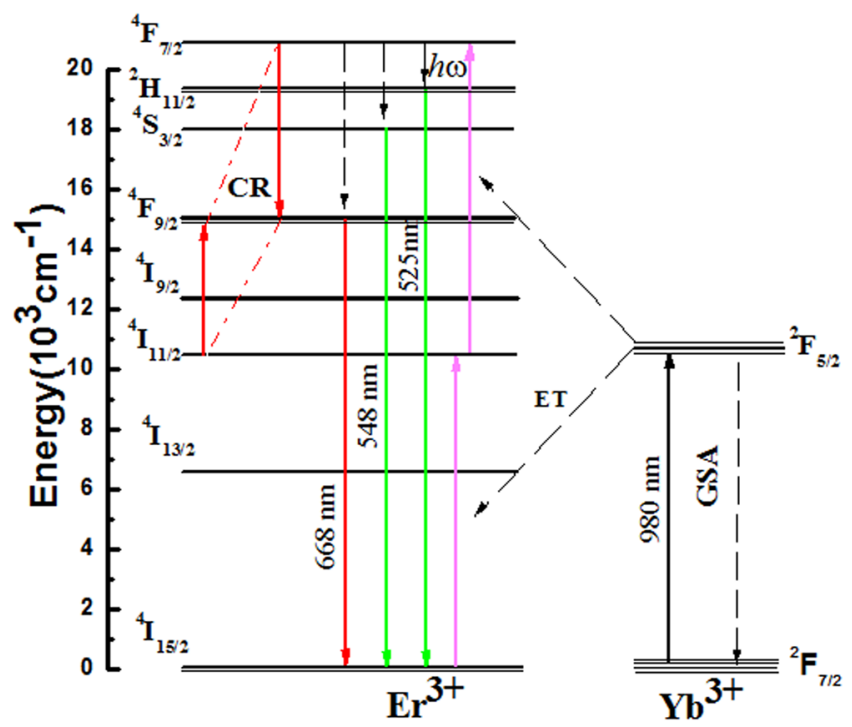

Figure 6. Energy level diagram of $\mathrm{Er}^{3+} / \mathrm{Yb}^{3+}$ and energy transfer progress.

crystals. Thus, the quadratic dependence indicates that blue, green and red emissions all arise from two-photon UC processes.

To better understand the mechanism of UC luminescence in $\mathrm{Er}^{3+} / \mathrm{Yb}^{3+}$ co-doped $\mathrm{Na}_{5} \mathrm{Lu}_{9} \mathrm{~F}_{32}$ single crystal, a schematic energy level diagram of $\mathrm{Er}^{3+} / \mathrm{Yb}^{3+}$ and the energy transfer process has been presented in Fig. 6. Following the $980 \mathrm{~nm}$ pumping light, the ${ }^{4} \mathrm{I}_{11 / 2}$ level of $\mathrm{Er}^{3+}$ ion can be directly excited from ground state ${ }^{4} \mathrm{I}_{15 / 2}$ or by energy transfer (ET) process from ${ }^{2} \mathrm{~F}_{5 / 2}$ level of $\mathrm{Yb}^{3+}$ to $\mathrm{Er}^{3+}:{ }^{2} \mathrm{~F}_{5 / 2}\left(\mathrm{Yb}^{3+}\right)+{ }^{4} \mathrm{I}_{15 / 2}\left(\mathrm{Er}^{3+}\right) \rightarrow{ }^{2} \mathrm{~F}_{7 / 2}\left(\mathrm{Yb}^{3+}\right)+{ }^{4} \mathrm{I}_{11 / 2}$ $\left(\mathrm{Er}^{3+}\right)$. It should be noted that interactions between two $\mathrm{Er}^{3+}$ ions cannot necessarily be ignored. An NIR photon can populate an $\mathrm{Er}^{3+}$ ion to its ${ }^{4} \mathrm{I}_{11 / 2}$ state directly. Another $\mathrm{Er}^{3+}$ ion also in the ${ }^{4} \mathrm{I}_{11 / 2}$ state and in close proximity will transfer its energy to the initial ion, thereby exciting it to the ${ }^{4} \mathrm{~F}_{7 / 2}$ state. However, the absorption cross section of $\mathrm{Yb}^{3+}$ at $\sim 980 \mathrm{~nm}$ is much larger than that of $\mathrm{Er}^{3+}:{ }^{4} \mathrm{I}_{11 / 2}$, which can be seen from Fig. 2, resulting in the ET process from $\mathrm{Yb}^{3+}$ to $\mathrm{Er}^{3+}$ is dominant in the excitation of $\left(\mathrm{Er}^{3+}\right)$ level. It is known that when co-doped samples are excited by high power successive laser at $980 \mathrm{~nm}$, the $\mathrm{Er}^{3+}$ ion may decay non-radiatively from the ${ }^{4} \mathrm{I}_{11 / 2}$ state to the ${ }^{4} \mathrm{I}_{13 / 2}$ state following the initial energy transfer from the $\mathrm{Yb}^{3+}$ ion by multi-phonon relaxation in recent works. However, bridging the energy gaps of ${ }^{4} \mathrm{I}_{11 / 2} \rightarrow{ }^{4} \mathrm{I}_{13 / 2}\left(3619 \mathrm{~cm}^{-1}\right)$ or ${ }^{4} \mathrm{~S}_{3 / 2} \rightarrow{ }^{4} \mathrm{~F}_{9 / 2}\left(3217 \mathrm{~cm}^{-1}\right)$ requires at least 6-7 phonons, multi-phonon relaxation will rarely happen in $\mathrm{Na}_{5} \mathrm{Lu}_{9} \mathrm{~F}_{32}$ single crystal due to its relatively low phonon energies about $\sim 441 \mathrm{~cm}^{-121}$. Thus, the excitation in the ${ }^{2} \mathrm{~F}_{7 / 2} \rightarrow{ }^{2} \mathrm{~F}_{5 / 2}$ transition of $\mathrm{Yb}^{3+}$ is followed by a two-step ET process to neighbouring $\mathrm{Er}^{3+}$ ions as shown in Fig. 6, which brings $\mathrm{Er}^{3+}$ to the ${ }^{4} \mathrm{~F}_{7 / 2}$ level. The populated ${ }^{4} \mathrm{~F}_{7 / 2}$ level of $\mathrm{Er}^{3+}$ then non-radiatively relaxes fast to the lower ${ }^{2} \mathrm{H}_{11 / 2}$ and ${ }^{4} \mathrm{~S}_{3 / 2}$ states because of the smaller energy gaps of ${ }^{4} \mathrm{~F}_{7 / 2} \rightarrow{ }^{2} \mathrm{H}_{11 / 2}\left(1162 \mathrm{~cm}^{-1}\right)$ and ${ }^{2} \mathrm{H}_{11 / 2} \rightarrow{ }^{4} \mathrm{~S}_{3 / 2}\left(794 \mathrm{~cm}^{-1}\right)$, and two green emissions then be observed. Above process generates two ${ }^{2} \mathrm{H}_{11 / 2} \rightarrow{ }^{4} \mathrm{I}_{15 / 2}$ and ${ }^{4} \mathrm{~S}_{3 / 2} \rightarrow{ }^{4} \mathrm{I}_{15 / 2}$ transitions centered at 525 and $548 \mathrm{~nm}$, respectively. Meanwhile, red emission band is attributed to the ${ }^{4} \mathrm{~F}_{9 / 2} \rightarrow{ }^{4} \mathrm{I}_{15 / 2}$ de-excitation process. And the population on ${ }^{4} \mathrm{~F}_{9 / 2}$ should come from the CR process of ${ }^{4} \mathrm{~F}_{7 / 2}+{ }^{4} \mathrm{I}_{11 / 2} \rightarrow{ }^{4} \mathrm{~F}_{9 / 2}+{ }^{4} \mathrm{~F}_{9 / 2}$, which can be evidenced by the $\mathrm{Yb}^{3+}$ concentration-dependent UCL spectra of $\mathrm{Na}_{5} \mathrm{Lu}_{9} \mathrm{~F}_{32}: \mathrm{Yb}^{3+}, \mathrm{Er}^{3+}$ single crystals (Fig. 3) as well as the decay curves of the $\mathrm{Er}^{3+} / \mathrm{Yb}^{3+}$ co-doped $\mathrm{Na}_{5} \mathrm{Lu}_{9} \mathrm{~F}_{32}$ single crystals surveyed at $548 \mathrm{~nm}$ (Fig. 4). As shown in the Fig. 3, When the concentration of $\mathrm{Yb}^{3+}$ increases to about $7.97 \mathrm{~mol} \%$, probably due to concentration quenching between $\mathrm{Er}^{3+}$ and $\mathrm{Yb}^{3+}$ ions, the energy transfer process of $\mathrm{Er}^{3+}\left({ }^{4} \mathrm{I}_{11 / 2}\right)+\mathrm{Yb}^{3+}\left({ }^{2} \mathrm{~F}_{5 / 2}\right) \rightarrow \mathrm{Er}^{3+}\left({ }^{4} \mathrm{~F}_{7 / 2}\right)+\mathrm{Yb}^{3+}\left({ }^{2} \mathrm{~F}_{7 / 2}\right)$ reduced accordingly, which leads to the reduction of the population of ${ }^{4} \mathrm{~F}_{7 / 2}$ state of $\mathrm{Er}^{3+}$ ions and results in the decrease of $525 \mathrm{~nm}$ and $548 \mathrm{~nm}$ emissions. Thus the strongest emissions at $525 \mathrm{~nm}$ and $548 \mathrm{~nm}$ in this study is observed when the $\mathrm{Yb}^{3+}$ is about $1.99 \mathrm{~mol} \%$. However, the process of two photon UC process $2^{2} \mathrm{~F}_{5 / 2}\left(\mathrm{Yb}^{3+}\right)+{ }^{4} \mathrm{I}_{15 / 2}\left(\mathrm{Er}^{3+}\right) \rightarrow 2^{2} \mathrm{~F}_{7 / 2}\left(\mathrm{Yb}^{3+}\right)+{ }^{4} \mathrm{~F}_{7 / 2}\left(\mathrm{Er}^{3+}\right)$ continues to increase luminescence intensify as the $\mathrm{Yb}^{3+}$ concentration increases. The concentration quenching between $\mathrm{Yb}^{3+}$ and $\mathrm{Yb}^{3+}$ ions has not been observed in this study.

UC external quantum efficiency of $\mathrm{Na}_{5} \mathrm{Lu}_{9} \mathrm{~F}_{32}: 1 \% \mathrm{Er}^{3+}, 7.9 \% \mathrm{Yb}^{3+}$. Having analyzed all the results above, pump-power dependent of UC external quantum efficiency (EQE) of $\mathrm{Na}_{5} \mathrm{Lu}_{9} \mathrm{~F}_{32}: 1 \mathrm{~mol}^{2} \mathrm{Er}^{3+} / 7.9 \% \mathrm{~mol}$ $\mathrm{Yb}^{3+}$ under the excitation of NIR $\sim 980 \mathrm{~nm}$ light was measured by an integrating sphere and displayed in Fig. 7(a). Following the $980 \mathrm{~nm}$ excitation, it should be noted that the EQE increases with the excitation power density, and the optimum EQE was about $6.80 \%$ under $5.5 \mathrm{Wcm}^{-2} 980 \mathrm{~nm}$ light excitation. And once the power density overpasses $5.5 \mathrm{Wcm}^{-2}$, the EQE of UCL hardly changed. In order to verify this point further, we calculated the theoretical EQE based on steady-state rate equations. On account of the simplified model shown in Fig. 7(a) above, the UC external quantum efficiency $\left(\mathrm{n}_{\mathrm{IOE}}\right)$ can be estimated by following equations: 

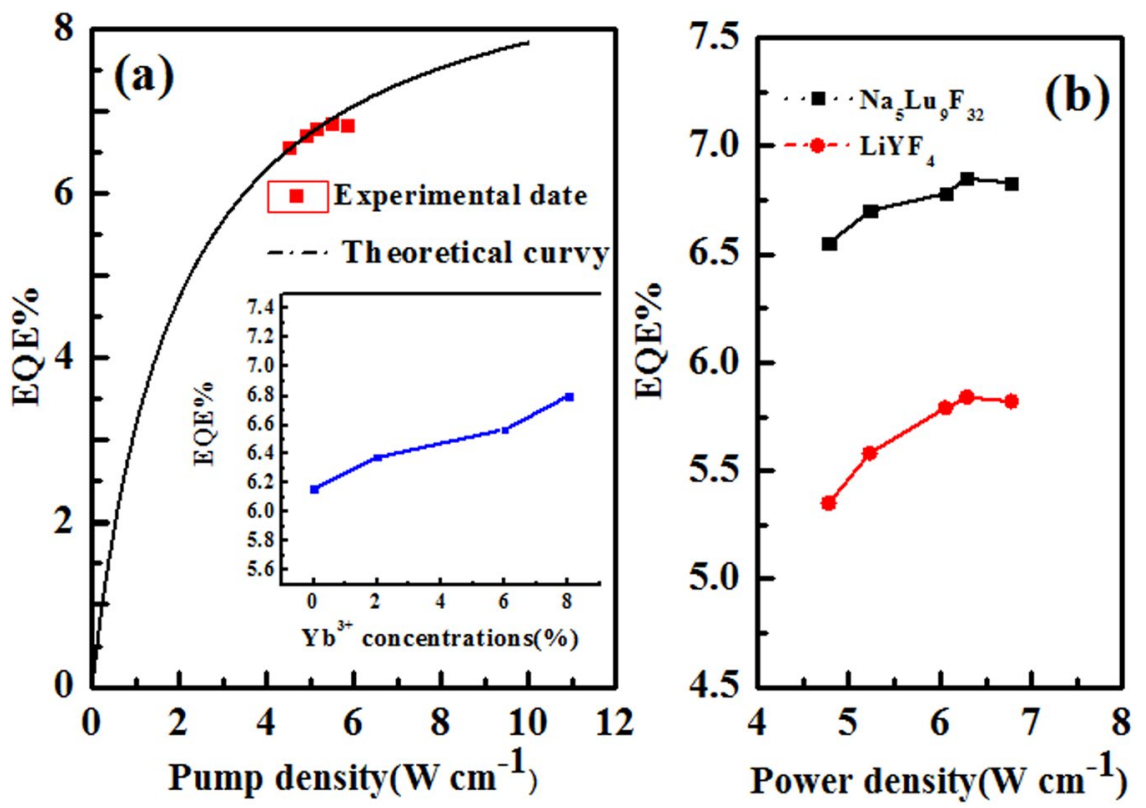

Figure 7. (a) Power-dependent UC external quantum efficiency at $980 \mathrm{~nm}$ light excitation in $\mathrm{Er}^{3+} / \mathrm{Yb}^{3+}$ doped $\mathrm{Na}_{5} \mathrm{Lu}_{9} \mathrm{~F}_{32}$ single crystals, the inset shows the external quantum efficiency on $\mathrm{Yb}^{3+}$ concentrations; (b) Comparison of UC external quantum efficiency of $\mathrm{Er}^{3+} / \mathrm{Yb}^{3+}$ co-doped $\mathrm{Na}_{5} \mathrm{Lu}_{9} \mathrm{~F}_{32} / \mathrm{LiYF}_{4}$ single crystals under $980 \mathrm{~nm}$ excitation.

$$
\begin{gathered}
c_{0} N_{0} N_{Y b 1}-c_{1} N_{1} N_{Y b 2}-W_{1} N_{1}=0 \\
c_{1} N_{1} N_{Y b 2}-W_{2} N_{2}=0 \\
N_{0}+N_{1}+N_{2}=N_{e r} \\
N_{Y b 1}+N_{Y b 2}=N_{Y b} \\
N_{Y b 2}=\rho_{P} \sigma N_{Y b 1} \\
\rho_{P}=\frac{\lambda_{P} I_{P}}{h c \pi \omega_{p} \wedge 2}=\frac{\lambda_{p}}{h c} P \\
N_{2}=\frac{c_{o} c_{1} N_{c} N_{Y b} \wedge 2 \rho_{P} \wedge 2 \sigma \wedge 2}{\left[W_{1} W_{2}+c_{0} c_{1} N_{Y b} \wedge 2+\left(c_{0}+c_{1}\right) N_{Y b}\right] \rho \wedge 2 \sigma \wedge 2+\left[\left(c_{0}+c_{1}\right) N_{Y b} W_{2}+2 W_{1} W_{2}\right] \rho \sigma+W_{1} W_{2}} \\
\eta=\frac{W_{2} N_{2}}{\rho_{P} \sigma N_{Y b 0}}=\frac{4.38 P}{1+0.51 P} \%
\end{gathered}
$$

where $c_{0}$ and $c_{1}$ are the ET coefficients for the UC processes between the donor and the acceptor in ${ }^{4} \mathrm{I}_{15 / 2}$ and ${ }^{4} \mathrm{I}_{9 / 2}$ states, respectively. $\mathrm{N}_{2}, \mathrm{~N}_{1}$, and $\mathrm{N}_{0}$ are the population ${ }^{2} \mathrm{H}_{11 / 2} /{ }^{4} \mathrm{~S}_{3 / 2}{ }^{4}, \mathrm{I}_{9 / 2}$, and ${ }^{4} \mathrm{I}_{15 / 2}$ densities of the levels of the $\mathrm{Er}^{3+}$ ions. And the $\mathrm{N}_{\mathrm{Yb} 1}$ and $\mathrm{N}_{\mathrm{Yb} 2}$ represent the ${ }^{2} \mathrm{~F}_{7 / 2}$ and ${ }^{2} \mathrm{~F}_{5 / 2}$ levels of $\mathrm{Yb}^{3+}$ ions, respectively. $\mathrm{N}_{\mathrm{Yb}}$ and Ner are the concentrations of the $\mathrm{Yb}^{3+}$ ions and the $\mathrm{Er}^{3+}$ ions. $\mathrm{W}_{1}$ denotes the non-radiative relaxation rate from level ${ }^{4} \mathrm{I}_{11 / 2}$ to lower state of $\mathrm{Er}^{3+}, \mathrm{W}_{2}$ is the radiative decay rate from level ${ }^{2} \mathrm{H}_{11 / 2} /{ }^{4} \mathrm{~S}_{3 / 2}$ to ground state of $\mathrm{Er}^{3+}$, and $\sigma$ is the $\mathrm{Yb}^{3+}$ absorption cross section at the pumping wavelength. The symbol $\rho_{\mathrm{P}}$ denotes the excitation power variable, given by equation (3). Here, $I_{P}$ is the incident pump power, $\lambda_{P}$ and $\omega_{P}$ are the pump wavelength and beam radius, respectively, $h$ is Planck's constant, and $c$ is the speed of light. $\mathrm{P}$ is the incident pump power density. From the above equations, we can obtain the population of ${ }^{2} \mathrm{H}_{11 / 2} /{ }^{4} \mathrm{~S}_{3 / 2}$ level using equation (4). Thus, the UC external quantum efficiency (EQE) can be deduced by equation (5). The calculated results were also plotted a line in Fig. 7(a). It can be noted that the theoretical measurement in accordance with the experimental dates. Generally, there exists the thermal effect in the nano-crystals ${ }^{21,22}$, which results into reduction of the quantum efficiency. It can be confirmed that the rare earth ion doped $\mathrm{Na}_{5} \mathrm{Lu}_{9} \mathrm{~F}_{32}$ single crystal has advantage of achieving high quantum efficiency and high thermal stability compared with its nano-crystal. The inset of the Fig. 7(a) shows the integrated external quantum efficiency on $\mathrm{Yb}^{3+}$ concentrations. The relative amount of $\mathrm{Yb}^{3+}$ ions tends to improve the EQE in $\mathrm{Er}^{3+} /$ $\mathrm{Yb}^{3+}$ co-doped $\mathrm{Na}_{5} \mathrm{Lu}_{9} \mathrm{~F}_{32}$ single crystals obviously, thus we have investigated the impact of various ytterbium concentrations on the EQE of the up-conversion progress under the same experiment condition. It is shown in the inset of Fig. 7(a) that EQE of up-conversion increases as the $\mathrm{Yb}^{3+}$ concentration increases monofonically and reaches its maximum value at $\sim 6.80 \%$ when $\mathrm{Yb}^{3+}$ concentration is $7.97 \mathrm{~mol} \%$. To testify the good UCL effect 


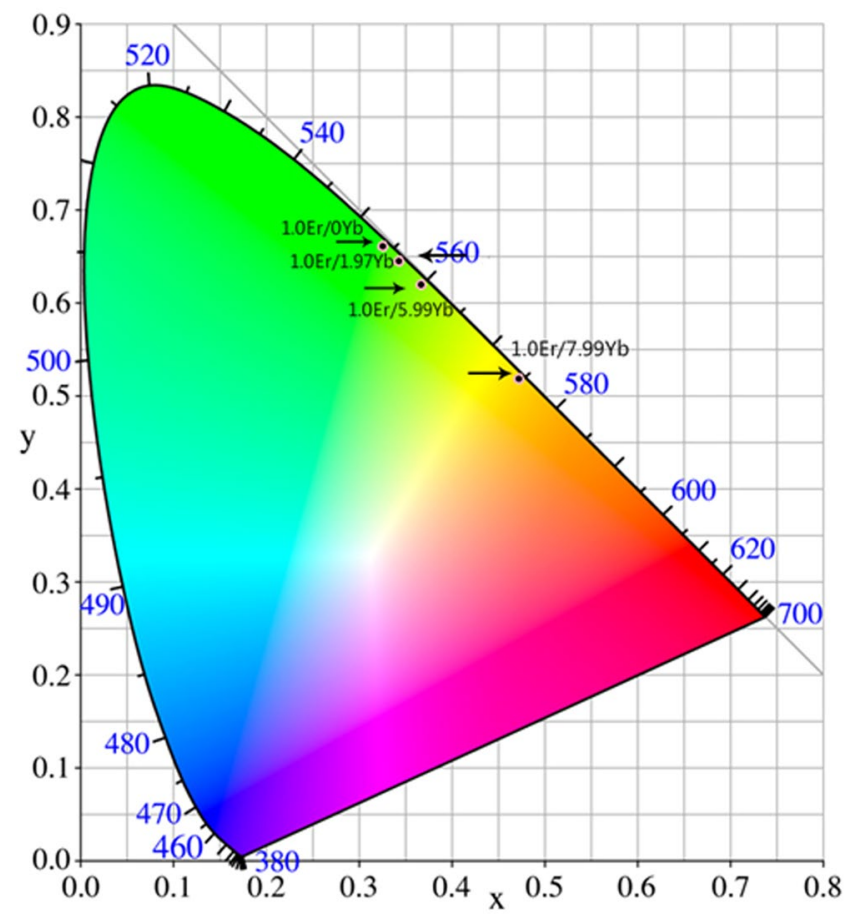

Figure 8. CIE chromaticity coordinates of $\mathrm{Er}^{3+} / \mathrm{Yb}^{3+}$ co-doped $\mathrm{Na}_{5} \mathrm{Lu}_{9} \mathrm{~F}_{32}$ single crystals.

in $\mathrm{Er}^{3+} / \mathrm{Yb}^{3+}$ co-doped $\mathrm{Na}_{5} \mathrm{Lu}_{9} \mathrm{~F}_{32}$ single crystals, we also compare them with $\mathrm{Er}^{3+} / \mathrm{Yb}^{3+}$ co-doped LiYF sam- $^{-}$ ples in Fig. 7(b) whose maximum EQE of up-conversion is about $\sim 5.8 \%{ }^{23}$. It is known that $\beta-\mathrm{NaYF}_{4}$ is widely accepted as the most efficient up-conversion host in the world. The $\mathrm{Er}^{3+} / \mathrm{Yb}^{3+}(2 \mathrm{~mol} \% / 18 \mathrm{~mol} \%)$ doped $\beta-\mathrm{NaYF}_{4}$ nano-crystal reaches its maximum QY at $\sim 4.8 \%{ }^{24}$. It should be noticed that $\mathrm{Er}^{3+} / \mathrm{Yb}^{3+}$ co-doped $\mathrm{Na}_{5} \mathrm{Lu}_{9} \mathrm{~F}_{32}$ single crystals can achieve higher external quantum efficiency at the lower power density, which indicates the $\mathrm{Er}^{3+} / \mathrm{Yb}^{3+}$ co-doped $\mathrm{Na}_{5} \mathrm{Lu}_{9} \mathrm{~F}_{32}$ single crystals own a better UCL effect and worth of further study.

CIE chromaticity coordinates of $\mathrm{Er}^{3+} / \mathrm{Yb}^{3+}$ co-doped $\mathrm{Na}_{5} \mathrm{Lu}_{9} \mathrm{~F}_{32}$ single crystal samples. Since the observed UC emissions are located in visible wavelength area, the exact UC luminescence CIE chromaticity coordinates of all the $\mathrm{Er}^{3+} / \mathrm{Yb}^{3+}$ co-doped $\mathrm{Na}_{5} \mathrm{Lu}_{9} \mathrm{~F}_{32}$ single crystal samples are shown in Fig. 8 to obtain the true color of the UC emissions. The CIE coordinates $(x, y)$ are $(0.3254,0.6612),(0.3422,0.6450),(0.3666,0.6202)$, and $(0.4721,0.5188)$ respectively, for $\mathrm{Er}^{3+} / \mathrm{Yb}^{3+}$ co-doped samples with $1.0 \mathrm{Er} / 0 \mathrm{Yb}, 1.0 \mathrm{Er} / 1.97 \mathrm{Yb}, 1.0 \mathrm{Er} / 5.99 \mathrm{Yb}$, and $1.0 \mathrm{Er} / 7.97 \mathrm{Yb}$ doping concentrations. From the CIE chromaticity coordinates, it is clear that the combination of the UC emission is yellowish green color to which human eyes are sensitive. This characteristic is favorable for applications in UC displays for electro-optical devices.

\section{Conclusions}

Following excitation with a $980 \mathrm{~nm}$ diode laser, the $\mathrm{Er}^{3+} / \mathrm{Yb}^{3+}$ co-doped $\mathrm{Na}_{5} \mathrm{Lu}_{9} \mathrm{~F}_{32}$ single crystals can be grown by a vertical Bridgman method and an enhanced up-conversion green and red lights can be obtained. Study on the pump power dependent UC spectra shows that the UC emissions of the green and red lights arise from two-photon process from excited $\mathrm{Yb}^{3+}$ to $\mathrm{Er}^{3+}$ energy transfer. The combination of the UC green and red lights yields a yellowish green light to which human eyes are very sensitive. The up-conversion quantum efficiency of $\mathrm{Er}^{3+} / \mathrm{Yb}^{3+}$ co-doped $\mathrm{Na}_{5} \mathrm{Lu}_{9} \mathrm{~F}_{32}$ single crystal under $5.5 \mathrm{Wcm}^{-2} 980 \mathrm{~nm}$ light excitation was as high as $6.80 \%$. Such $\mathrm{Er}^{3+} / \mathrm{Yb}^{3+}$ co-doped $\mathrm{Na}_{5} \mathrm{Lu}_{9} \mathrm{~F}_{32}$ single crystals may have potential applications in the fields of biosensors, infrared pumped visible eye-safe lasers, optical telecommunication and UC displaying devices due to its low phonon energy, high luminous efficiency, high transmittance for light and stability in chemical-physical properties.

\section{Experimental}

Materials. $\mathrm{Er}^{3+} / \mathrm{Yb}^{3+}$ co-doped samples were grown by an improved Bridgman method according to the formula $30 \mathrm{NaF}-18 \mathrm{KF}-(52-\chi-\gamma) \mathrm{YF}_{3}-\chi \mathrm{ErF}_{3}-\gamma \mathrm{YbF}_{3}(\chi=1.0, \gamma=0,26,8)$, respectively, with 99.99\% purity raw materials of $\mathrm{NaF}, \mathrm{LuF}_{3}, \mathrm{ErF}_{3}$, and $\mathrm{YbF}_{3}$.

Synthesis of $\mathrm{Na}_{5} \mathrm{Lu}_{9} \mathrm{~F}_{32}: \mathrm{Er}^{3+} / \mathrm{Yb}^{3+}$ single crystals. Then these mixture samples were ground thoroughly in a mortar for about $0.5 \mathrm{~h}$. In order to remove the moisture and the oxide in the raw materials, the mixtures were sintered with anhydrous $\mathrm{HF}$ at $750^{\circ} \mathrm{C}$ for $8 \mathrm{~h}$. The seed crystals were oriented along a-axis. The seeding temperature was about $770-820^{\circ} \mathrm{C}$ and the temperature gradient cross solid-liquid interface was $70-90^{\circ} \mathrm{C} / \mathrm{cm}$. The growing process was carried out by lowering the crucible at a rate of $0.05-0.06 \mathrm{~mm} / \mathrm{h}$. The detailed process was similar to that reported elsewhere ${ }^{25}$. Figure 1(a) shows the boule of as-grown single crystal and the polished slice of crystal with $1.50 \mathrm{~mm}$ thickness. The single crystal appears high transparency and pink. 


\begin{tabular}{|c|c|c|c|c|}
\hline \multirow[b]{2}{*}{ Samples } & \multicolumn{2}{|l|}{$\mathrm{Er}^{3+}$} & \multicolumn{2}{|l|}{$\mathbf{Y b}^{3+}$} \\
\hline & \begin{tabular}{|l|}
$\begin{array}{l}\text { Molar concentration } \\
(\mathrm{mol} \%)\end{array}$
\end{tabular} & $\begin{array}{l}\text { The number of } \\
\text { ion }\left(10^{20} \text { ions } / \mathrm{cm}^{-3}\right)\end{array}$ & $\begin{array}{l}\text { Molar concentration } \\
\text { (mol\%) }\end{array}$ & \begin{tabular}{|l} 
The number of ion \\
$\left(10^{20}\right.$ ions $\left./ \mathrm{cm}^{-3}\right)$
\end{tabular} \\
\hline NFEY1 & 0.98 & 1.512 & 0 & 0 \\
\hline NFEY2 & 0.99 & 1.503 & 1.97 & 1.978 \\
\hline NFEY6 & 1.01 & 1.502 & 5.99 & 6.028 \\
\hline NFEY8 & 0.99 & 1.506 & 7.97 & 8.02 \\
\hline
\end{tabular}

Table 1. The measured molar concentrations and the number of $\mathrm{Er}^{3+}$ and $\mathrm{Yb}^{3+}$ in $\mathrm{Na}_{5} \mathrm{Lu}_{9} \mathrm{~F}_{32} \mathrm{crystal}_{\text {. }}$

Characterization. X-ray diffraction (XRD) of the samples was measured using a D8 Advance diffractometer (BRUKER, German). The absorption spectra were recorded with a Cary 5000 UV/VIS/NIR spectrophotometer (Agilent Co., America). The emission spectra were obtained with a FLSP 920 type spectrometer (Edinburgh Co., England). The external quantum efficiency were measured by a fluorescence spectrometer (FLS 980) of Edinburgh instruments combined with an integrating sphere. All the measurements were measured at room temperature. The actual concentrations of $\mathrm{Er}^{3+}$ and $\mathrm{Yb}^{3+}$ ions in all the samples were measured by an inductively coupled plasma atomic emission spectroscopy (ICP-AES, Perk in Elmer Inc., Optima 3000). The measured $\mathrm{Er}^{3+}$ and $\mathrm{Yb}^{3+}$ concentrations in all crystals are presented in Table 1.

\section{References}

1. Bloembergen, N. Solid State Infrared Quantum Counters. Phys. Rev. Lett. 2, 84 (1959)

2. Liu, F., Zhao, Q., You, H. \& Wang, Z. Synthesis of stable carboxy-terminated NaYF4: $\mathrm{Yb}^{3+}, \mathrm{Er}^{3+} @ S i O 2$ nanoparticles with ultrathin shell for biolabeling applications. Nanoscale. 5(3), 1047-1053 (2013).

3. Macdonald, D., Mclean, K., Deenapanray, P. N. K., Dewolf, S. \& Schmidt, J. Electronically-coupled up-conversion: an alternative approach to impurity photovoltaics in crystalline silicon. Semicond. Sci. Technol. 23(1), 015001 (2008).

4. Boyer, J. C. et al. Investigation of the upconversion processes in nanocrystalline $\mathrm{Gd}_{3} \mathrm{Ga}_{5} \mathrm{O}_{12}: \mathrm{Ho}^{3+}$. J. Lumen. 106, 263-268 (2004).

5. Zhang, H. X. et al. Deposition and photoluminescence of sol-gel derived $\mathrm{Tb}^{3+}: \mathrm{Zn}_{2} \mathrm{SiO}_{4}$ films on SiO $2 / S i$. Thin Solid Films. 370, 50-53 (2000).

6. Renero-Lecuna, C. et al. Synthesis of cubic and hexagonal NaYF4: $E^{3+}$. Chem. Mater. 23, 3442-3448 (2011)

7. Chan, E. M. et al. Combinatorial discovery of lanthanide-doped nanocrystals with spectrally pure upconverted emission. Nano. Lett. 12, 3839-3845 (2012)

8. Wang, F., Wang, J. \& Liu, X. Direct evidence of a surface quenching effect on size-dependent luminescence of upconversion nanoparticles. Angew. Chem., Int. Ed. 49, 7456-7460 (2010).

9. Zhao, J. et al. Upconversion luminescence with tunable lifetime in $\mathrm{NaYF}_{4}: \mathrm{Yb}$, Er nanocrystals: role of nanocrystal size. Nanoscale. 5, 944-952 (2013).

10. Treadaway, M. J. \& Powell, R. C. Luminescence of calcium tungstate crystals. J. Chem. Phys. 61, 4003-4011 (1974).

11. Liu, J. et al. Room temperature synthesis and optical properties of $\mathrm{SrMoO}_{4}$ crystallites by w/o microemulsion. Ceram. Int. 34, 1557-1560 (2008).

12. Cavalcante, L. S. et al. Photoluminescent Behavior of BaWO4 Powders Processed in Microwave-Hydrothermal. J. Alloy. Compd. 474, 195-200 (2009).

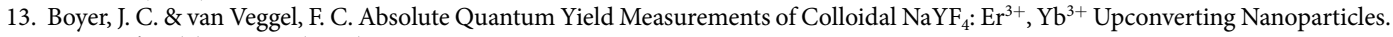
Nanoscale. 2(8), 1417-9 (2010).

14. Shmyt'ko, I. M. \& Strukova, G. K. Fine sructure of $\mathrm{Na}_{5} \mathrm{Lu}_{9} \mathrm{~F}_{32}$, nanocrystallites formed at the initial stages of crystallization. Phys Solid State. 51(9), 1907-1911 (2009).

15. Lv, R. et al. Lutecium Fluoride Hollow Mesoporous Spheres with Enhanced Up-Conversion Luminescent Bioimaging and LightTriggered Drug Release by Gold Nanocrystals. Acs Appl Mater Inter. 6(17), 15550-15563 (2014).

16. Thoma, R. E., Insley, H. \& Hebert, G. M. The Sodium Fluoride-Lanthanide Trifluoride Systems. Inorg. Chem. 5(7), 1222-1229 (1966).

17. Li, C. \& Lin, J. Rare earth fluoride nano-/microcrystals: synthesis, surface modification and application. J. Mater. Chem. 20, 6831 (2010).

18. Li, C. et al. Spectral properties of Tm, Ho: $\mathrm{LiYF}_{4}$ laser crystal. J. Rare Earth. 29, 592 (2011).

19. Kozlov, S. A. et al. Segregation Behavior of Impurities in Gallium during Directional Solidification. Inorg. Mater. 39(5), 452-454 (2003).

20. Auzel, F. Upconversion and Anti-Stokes Processes with $\mathrm{f}$ and $\mathrm{d}$ Ions in Soilids. Chem. Rev. 104, 139 (2004).

21. Chen, X. et al. Large Upconversion Enhancement in the "Islands" Au-Ag Alloy/ $\mathrm{NaYF}_{4}: \mathrm{Yb}^{3+}, \mathrm{Tm}^{3+} / \mathrm{Er}^{3+} \mathrm{Composite}^{\mathrm{Films}}$, and Fingerprint Identification. Adv. Funct. Mater. 25, 5462 (2015)

22. Suyver, J. F., Aebischer, A., García-Revilla, S., Gerner, P. \& Güdel, H. U. Anomalous Power Dependence of Sensitized Upconversion Luminescence. Phys. Rev. B: Condens. Matter Mater. Phys. 71, 125123 (2005).

23. Chen, X. et al. Highly Efficient $\mathrm{LiYF}_{4}: \mathrm{Yb}^{3+}, \mathrm{Er}^{3+}$ Upconversion Single Crystal under Solar Cell Spectrum Excitation and Photovoltaic Application. Acs Appl Mater Inter. 8(14), 9071 (2016).

24. Dyck et al. Size-Dependent Maximization of Upconversion Efficiency of; Citrate-Stabilized ss-phase $\mathrm{NaYF}_{4}: \mathrm{Yb}^{3+}, \mathrm{Er}^{3+} \mathrm{Crystals} \mathrm{via}$ Annealing. ACS Appl Mater Inter. 5(22), 11661-11667 (2013).

25. Hang, J., Xia, H., Jiang, Y. \& Yang, S. Efficient Quantum Cutting in $\mathrm{Tb}^{3+} / \mathrm{Yb}^{3+}$ Codoped, $\alpha-\mathrm{NaYF}_{4}$ Single Crystals Grown by Bridgman Method Using KF Flux for Solar Photovoltaic. IEEE J Quantum Elect. 51(6), 1-6 (2015).

\section{Acknowledgements}

This work was supported by the National Natural Science Foundation of China (Grant No. 5177020477) and (Grant No. 51472125), the Natural Science Foundation of Zhejiang Province (Grant No. LZ17E020001), Natural Science Foundation of Henan Province (Grant no. U1504626), Fundamental Research Funds for the Central Universities (Grant No. 3132016333), and K.C. Wong Magna Fund in Ningbo University. 


\section{Author Contributions}

Shinan He prepared the samples and wrote the first edition of the manuscript. Haiping Xia made the research proposal and provided the financial support for this work, and also took the responsibility of all correspondence. Jianli Zhang measured all the spectra. Yongsheng Zhu provided the supports of measurements of UC efficiency. Baojiu Chen gave suggestions for the spectral analyses; meanwhile he also took the responsibility of correspondence.

\section{Additional Information}

Competing Interests: The authors declare that they have no competing interests.

Publisher's note: Springer Nature remains neutral with regard to jurisdictional claims in published maps and institutional affiliations.

(c) (i) Open Access This article is licensed under a Creative Commons Attribution 4.0 International

License, which permits use, sharing, adaptation, distribution and reproduction in any medium or format, as long as you give appropriate credit to the original author(s) and the source, provide a link to the Creative Commons license, and indicate if changes were made. The images or other third party material in this article are included in the article's Creative Commons license, unless indicated otherwise in a credit line to the material. If material is not included in the article's Creative Commons license and your intended use is not permitted by statutory regulation or exceeds the permitted use, you will need to obtain permission directly from the copyright holder. To view a copy of this license, visit http://creativecommons.org/licenses/by/4.0/.

(c) The Author(s) 2017 